DOI: 10.12731/2658-6649-2019-11-5-2-124-128

УДК 616.33-002.27

\title{
ПОКАЗАТЕЛИ НЕКОТОРЫХ ЦИТОКИНОВ У БОЛЬНЫХ ХРОНИЧЕСКИМ, ХРОНИЧЕСКИМ АТРОФИЧЕСКИМ ГАСТРИТОМ НА ФОНЕ HELICOBACTER PYLORI-ИНФЕКЦИИ
}

Синяков А.А., Смирнова О.В., Каспаров Э.В.

Бактерия Helicobacter pylori приводит к запуску цุитокинового каскада. В нашем исследовании мы изучили показатели некоторых цитокинов (ИЛ-2, ИЛ-4, ИЛ-8, TNF- $\alpha$, интерферона- $\gamma$ ) у больных хроническим гастритом и хроническим атрофическим гастритом на фоне Helicobacter pylori инфекции. Во всех группах больных хроническими гастритами и хроническими атрофическими гастритами с H. pylori инфекичией регистрировалось увеличение провоспалительных (ИЛ-2, интерферон- $\gamma$, ИЛ8) и противовоспалительных (ИЛ-4) цичтокинов.

Ключевые слова: ичитокины; гастриты; Helicobacter pylori.

\section{INDICATORS OF SOME CYTOKINES IN PATIENTS WITH CHRONIC, CHRONIC ATROPHIC GASTRITIS WITH HELICOBACTER PYLORI INFECTION}

\section{Sinyakov A.A., Smirnova O.V., Kasparov E.V.}

The bacterium Helicobacter pylori leads to the launch of the cytokine cascade. In our study, we studied the performance of some cytokines (IL-2, IL-4, IL-8, TNF- $\alpha$, interferon- $\gamma$ ) in patients with chronic gastritis and chronic atrophic gastritis in the background of Helicobacter pylori infection. In all groups of patients with chronic gastritis and chronic atrophic gastritis with $H$. pylori infection, an increase in pro-inflammatory (IL-2, interferon- $\gamma, I L-8)$ and anti-inflammatory (IL-4) cytokines was recorded.

Keywords: cytokines; gastritis; Helicobacter pylori.

\section{Введение}

При инфицировании бактерией Н. pylori происходит запуск цитокинового каскада, играющий ключевую роль в прогрессировании хронических воспалительных процессов в слизистой оболочке желудка. У больных 
инфицированных Н. pylori регистрируется стимуляция секреции целого ряда цитокинов, которые в свою очередь способствуют привлечению иммунокомпетентных клеток и развитию воспалительных изменений. Кроме того, происходит увеличение инфекционной нагрузки, атрофических изменений в слизистой оболочке желудка, и тем самым создаются условия для трансформации предракового состояния в рак $[1 ; 2 ; 3 ; 4,5]$. Целью данной работы было изучение некоторых цитокинов (ИЛ-2, ИЛ-4, ИЛ-8, TNF- $\alpha$, интерферона- $\gamma$ ) у больных хроническим гастритом и хроническим атрофическим гастритом на фоне Helicobacter pylori инфекции.

\section{Материалы и методы}

Контрольная группа состояла из 84 практически здоровых лиц (средний возраст 47,3 2,3 года), во вторую группу вошли 71 пациент с хроническим гастритом тела желудка (средний возраст $45,4+5,4$ лет) и третья группа, это 26 пациентов с выраженным атрофическим гастритом тела желудка (средний возраст 48,1+4,1 лет). Исследование проводилось с разрешения этического комитета «НИИ медицинских проблем Севера». Каждый участник подписывал форму информированного согласия на обследование, согласно Хельсинской Декларации Всемирной Медицинской Ассоциации, регламентирующей проведение научных исследований. Уровни ИЛ-2, ИЛ-4, ИЛ-8, TNF- $\alpha$, интерферона- $\gamma$ в сыворотке крови больных и здоровых лиц определяли ИФА с использованием наборов реагентов производства ЗАО «Вектор-Бест» (г. Новосибирск). Статистическая обработка данных осуществлялась с помощью пакета прикладных программ Statistica 7.0 (StatSoft, USA).

\section{Результаты исследования и обсуждения}

У больных хроническими гастритами с Н. pylori наблюдалось повышение содержания интерлейкина- $2\left(\mathrm{p}_{1-2}<0,001 ; \mathrm{p}_{1-3}<0,001\right)$ и интерлейкина- 8 больше чем в 10 раз $\left(\mathrm{p}_{1-2}<0,001 ; \mathrm{p}_{1-3}<0,001\right)$ по сравнению с контрольной группой. У больных хроническими гастритами с Н. pylori происходило повышение содержания интерферона-гамма в 1,5 раза относительно контрольной группы $\left(\mathrm{p}_{1-2}<0,001 ; \mathrm{p}_{1-3}<0,001\right)$. У больных хроническими гастритами с Н. pylori отмечалось повышение противовоспалительного цитокина интерлейкина-4 больше чем в 10 раз по сравнению с контрольной группой $\left(\mathrm{p}_{1-2}<0,001 ; \mathrm{p}_{1-3}<0,001\right)$.

Таким образом, во всех группах больных хроническими гастритами и хроническими атрофическими гастритами с Н. pylori инфекцией регистри- 
ровалось увеличение провоспалительных (ИЛ-2, интерферон- $\gamma$, ИЛ-8) и противовоспалительных (ИЛ-4) цитокинов, что может указывать на активацию и дисбаланс в системе цитокиновой регуляции. При инфицировании организма бактерией Н. pylori происходит стимуляция секреции ряда цитокинов, которые способствуют привлечению иммунокомпетентных клеток, развитию воспалительных изменений, тем самым происходит увеличение инфекционной нагрузки, что еще больше усложняет процесс восстановления организма.

Информация о конфликте интересов. Авторы заявляют об отсутствии конфликтов интересов

\section{Cиисок литературы/References}

1. Lu P.H., Tang Y., Li C. et al. Meta-analysis of association of tumor necrosis factor alpha-308 gene promoter polymorphism with gastric cancer / Zhonghua Yu Fang Yi Xue Za Zhi 2010. № 44(3), pp. 209-214.

2. Megraud F., Brassens-Rabbe M.P., Denis F. Seroepidemiology of Campylobacter pylori infection in various populations / J Clin Microbiol. 1989. № 27, pp. 1870-1873.

3. Sakamoto S., Ryan A. J., Kyprianou N. Targeting Vasculature in Urologic Tumors: Mechanistic and Therapeutic Significance // J. Cell Biochem. 2008. Vol. 103, N 3, pp. 691-708.

4. Yan L., Anderson G.M., DeWitte M., Nakada M.T. Therapeutic potential of cytokine and chemokine antagonists in cancer therapy // Eur. J. Cancer. 2006. Vol. 42, N 6, pp. 793-802.

5. Lukicheva E.V., Tonkikh J.L., Kasparov E.V., Tsukanov V.V., Vasyutin A.V. Lipid composition of bile, motor functions of the gallbladder and prevalence of biliary diseases in native inhabitants and new comers of Evenkia. Дальневосточный медицинский журнал. 2011. № 4, pp. 23-26.

6. Manchuk V.T., Smirnova O.V. Using methods of neural network modeling and discriminant analysis to assess the state of the immune status in patients with acute non-lymphoblastic leukemia. Yakut Medical Journal. 2010. № 2 (30), pp. 77-79.

\section{ДАННЫЕ ОБ АВТОРАХ}

Синяков Александр Александрович, к.б.н., младший научный сотрудник лаборатории клинической патофизиологии Федеральное государственное бюджетное научное учреждение «Федеральные исследовательский иентр «Красноярский научныий иентр Сибирского отделения Российской академии наук» - обосо- 
бленное подразделение «Научно-исследовательский институт медииинских проблем Севера»

ул. Партизана Железняка, 32, г. Красноярск, 660022, Российская Федерачия

sinyakov.alekzandr@mail.ru

Смирнова Ольга Валентиновна, д.м.н., доцент, профессор, заведующая лабораторией клинической патофизиологии

Федеральное государственное бюджетное научное учреждение "Федеральные исследовательский центр «Красноярский научныии иентр Сибирского отделения Российской академии наук» - обособленное подразделение «Научно-исследовательский институт медицинских проблем Севера»

ул. Партизана Железняка, 32, г. Красноярск, 660022, Российская Федераиия

ovsmirnova71@mail.ru

Каспаров Эдуард Вильямович, д.м.Н., профессор, директор НИИ МПС ФИЦ КНЦ СО РАН, зам. директора

Федеральное государственное бюджетное научное учреждение «Федеральные исследовательский иентр «Красноярский научный иентр Сибирского отделения Российской академии наук» - обособленное подразделение «Научно-исследовательский институт медицинских проблем Севера»

ул. Партизана Железняка, 32, г. Красноярск, 660022, Российская Федерация

impn@impn.ru

\section{DATA ABOUT THE AUTHORS}

Sinyakov Alexander Alexandrovich, Ph.D., Junior Researcher, Clinical Pathophysiology

Research Institute of Medical Problems of the North of the Federal Research Center Krasnoyarsk Scientific Center of the Siberian Branch of the Russian Academy of Sciences

3g, Partizan Zheleznyak Str., Krasnoyarsk, 660022, Russian Federation sinyakov.alekzandr@mail.ru

Smirnova Olga Valentinovna, Doctor of Medical Sciences, Associate Professor, Professor, Head laboratory of clinical pathophysiology 
128 Siberian Journal of Life Sciences and Agriculture, Vol 11, №5-2, 2019

Research Institute of Medical Problems of the North of the Federal Research Center Krasnoyarsk Scientific Center of the Siberian Branch of the Russian Academy of Sciences

3g, Partizan Zheleznyak Str., Krasnoyarsk, 660022, Russian Federation ovsmirnova71@mail.ru

Kasparov Eduard Vilyamovich, MD, Professor, Director

Research Institute of Medical Problems of the North of the Federal Research Center Krasnoyarsk Scientific Center of the Siberian Branch of the Russian Academy of Sciences

3g, Partizan Zheleznyak Str., Krasnoyarsk, 660022, Russian Federation impn@impn.ru 